\title{
IL-15, a survival factor for kidney epithelial cells, counteracts apoptosis and inflammation during nephritis
}

\author{
Michiya Shinozaki, ${ }^{1}$ Junichi Hirahashi, ${ }^{1}$ Tatiana Lebedeva, ${ }^{1}$ Foo Y. Liew, ${ }^{2}$ David J. Salant, ${ }^{3}$ \\ Ruth Maron, ${ }^{4}$ and Vicki Rubin Kelley ${ }^{1}$
}

${ }^{1}$ Laboratory of Molecular Autoimmune Disease, Renal Division, Brigham and Women's Hospital, Boston, Massachusetts, USA

${ }^{2}$ Department of Immunology and Bacteriology, University of Glasgow, Glasgow, United Kingdom

${ }^{3}$ Renal Section, Evans Biomedical Research Center, Boston University Medical Center, Boston, Massachusetts, USA

${ }^{4}$ Center for Neurological Disease, Brigham and Women's Hospital, Boston, Massachusetts, USA

Address correspondence to: Vicki Rubin Kelley, Harvard Institutes of Medicine, 77 Avenue Louis Pasteur,

Boston, Massachusetts 02115, USA. Phone: (617) 525-5915; Fax: (617) 525-5830; E-mail: vkelley@rics.bwh.harvard.edu.

Received for publication November 6, 2001, and accepted in revised form March 5, 2002.

\begin{abstract}
IL-15, a T cell growth factor, has been linked to exacerbating autoimmune diseases and allograft rejection. To test the hypothesis that IL-15-deficient $\left(I L-15^{-/-}\right)$mice would be protected from $\mathrm{T}$ cell-dependent nephritis, we induced nephrotoxic serum nephritis (NSN) in $I L-15^{-/-}$and wild-type $\left(I L-15^{+/+}\right)$C57BL/6 mice. Contrary to our expectations, IL-15 protects the kidney during this T cell-dependent immunologic insult. Tubular, interstitial, and glomerular pathology and renal function are worse in $I L-15^{-/}$mice during NSN. We detected a substantial increase in tubular apoptosis in $I L-15^{-/-}$kidneys. Moreover, macrophages and CD4 T cells are more abundant in the interstitia and glomeruli in $I L-15^{-/-}$mice. This led us to identify several mechanisms responsible for heightened renal injury in the absence of IL-15. We now report that IL-15 and the IL-15 receptor $(\alpha, \beta, \gamma$ chains) are constitutively expressed in normal tubular epithelial cells (TECs). IL-15 is an autocrine survival factor for TECs. TEC apoptosis induced with anti-Fas or actinomycin D is substantially greater in $I L-15^{-/-}$than in wild-type TECs. Moreover, IL-15 decreases the induction of a nephritogenic chemokine, MCP-1, that attracts leukocytes into the kidney during NSN. Taken together, we suggest that IL-15 is a therapeutic for tubulointerstitial and glomerular kidney diseases.
\end{abstract}

J. Clin. Invest. 109:951-960 (2002). DOI:10.1172/JCI200214574.

\section{Introduction}

In most kidney diseases, leukocytes in the kidney mediate tissue injury. The primary site of infiltration is the renal interstitium. The interaction of leukocytes with resident kidney cells stimulates these parenchymal cells to generate cytokines and incite an amplification cascade resulting in inflammation. Tubular epithelial cells (TECs), which comprise the vast majority of parenchymal cells in the kidney, are a rich source of cytokines and chemokines. The dynamics between the kidneyinfiltrating leukocytes and the TECs determine the extent of interstitial inflammation. Activated TECs generate numerous cytokines and chemokines that promote renal injury. IFN- $\gamma$ produced by $T$ cells is the most potent TEC activator. Since IL-15 is a T cell growth factor (1) that is expressed in IFN- $\gamma$-activated human kidney TECs (2), we concluded that IL-15 is a pivotal cytokine in kidney inflammation.

The biologic functions of IL-15 are complex. Although the receptors for IL-15 and IL-2 share two subunits (the IL-2 $\beta$ and common $\gamma$ chains), the functions of these molecules during $\mathrm{T}$ cell-dependent immune responses are distinct and contrasting (3). Specificity for IL-15 is conferred by the $\alpha$ chain of the IL-15 receptor (IL-15R) (4). While IL-15 and IL-2 have somewhat redundant properties in stimulating $\mathrm{T}$ cell proliferation, IL-15, unlike IL-2, does not promote T cell apoptosis. Indeed, IL-15 protects T cells from IL-2-triggered apoptosis (5). Moreover, IL-15 is of particular importance as a growth factor for memory CD8 $\mathrm{T}$ cells (6). In fact, mice genetically deficient in IL-15 have a reduction in memory CD8 T cells and NK cells (3).

Of particular importance, IL-15 and IL-2 are not expressed in the same cells. In contrast to the expression of IL- 2 in activated T cells, IL-15 is constitutively expressed by a broad array of cell types. Notably, epithelial cells are a principal source of IL-15. In keeping with this data, amplified IL-15 expression at the site of autoimmune disease has been linked to exacerbation of rheumatoid arthritis (7) and inflammatory bowel disease (8). Furthermore, enhanced IL-15 expression is detected in kidneys during human allograft rejection (9). Interestingly, IL-15 blockade with a neutralizing soluble IL-15R or a receptor site antagonist have proven effective in prolonging heart or islet allograft survival (10) and suppressing collagen-induced arthritis (11) and delayedtype hypersensitive reactions (12). Based on these findings, we deduced that preventing signaling via IL-15R $\alpha$ might be a therapeutic strategy for countering $\mathrm{T}$ cell-dependent immune reactions, particularly those involving epithelial cells. 
Since T cells mediate immunologic kidney diseases, we hypothesized that IL-15, a potent $\mathrm{T}$ cell growth factor produced by kidney TECs, would foster the expansion of activated $\mathrm{T}$ cells within the kidney and thus promote $\mathrm{T}$ cell-mediated renal injury. To test this hypothesis, we evaluated the role of IL-15 in IL-15-deficient $\left(I L-15^{-/-}\right)$and IL-15 intact $\left(I L-15^{+/+}\right)$mice during accelerated nephrotoxic serum nephritis (NSN), a T cell-dependent model of kidney disease (13). Contrary to our hypothesis, renal damage is more severe and macrophages and CD4 T cells are more abundant in $I L-15^{-/-}$mice than in $I L-15^{+/+}$mice. Although IL-15 is largely expressed by TECs in nephritic kidneys, it is far more abundant in normal kidneys. Why does a failure to express IL-15 lead to heightened renal injury? We now report that IL-15 functions in an autocrine manner as a survival factor for renal TECs. IL-15 serves to guard against TEC apoptosis. In addition, IL-15 inhibits the expression of the chemokine MCP-1. Perhaps as a consequence, the accumulation of macrophages and CD4 T cells is reduced. Thus, we suggest that IL-15 protects the kidney during certain immunologic assaults.

\section{Methods}

Mice. C57BL/6 mice genetically deficient in IL-15 (IL-15 $5^{-/}$mice ) were generated by gene targeting and generously provided by J.J. Peschon (Immunex Corp., Seattle, Washington, USA) (3). Age- and sex-matched C57BL/6 mice, referred to as $I L-15^{+/+}$wild-type mice (The Jackson Laboratory, Bar Harbor, Maine, USA), were used as controls. The mice were bred and maintained in a pathogen-free animal facility at Brigham and Women's Hospital.

NSN. Nephrotoxic serum was prepared as described previously (14). Nephrotoxic serum and nonimmune sheep control serum (Sigma Chemical Co., St. Louis, Missouri, USA) were filter-sterilized. To induce NSN, $I L-15^{-/-}$and $I L-15^{+/+}$mice (8-12 weeks of age) were primed subcutaneously in each flank with $1 \mathrm{mg}$ sheep IgG in Freund's complete adjuvant (Sigma Chemical Co.). Beginning 5 days later, the mice were challenged with intravenous injections of either $0.1 \mathrm{ml}$ of nephrotoxic serum or control serum for 3 consecutive days. Groups of mice were sacrificed at 6, 11, and 14 days after the initial challenge injection.

Blood urea nitrogen and proteinuria. Blood urea nitrogen (BUN) was measured in the serum prior to the initial challenge and on days 11 and 14 after the initial challenge with nephrotoxic serum, using the urea nitrogen kit from Sigma Chemical Co. Urine protein levels were assessed semiquantitatively using Albustix dipsticks (Bayer Diagnostics, Elkhart, Indiana, USA) on days 0, 5 , and 13 after the initial challenge with nephrotoxic serum or control serum. Urinary protein levels were confirmed by analyzing twice on each day.

Kidney pathology. After removing the kidneys, half of one kidney was bisected, fixed in $10 \%$ neutral buffered formalin, and embedded in paraffin. The other half was snap-frozen for immunostaining. The other kidney was used to prepare RNA. Paraffin sections were stained with periodic acid-Schiff reagent for routine histology. Pathology was evaluated using coded slides as previously described (15). We assessed glomerular pathology by evaluating more than 100 glomerular cross sections per kidney. The percentage of glomeruli with crescents (defined as two or more cell layers within Bowman's space) and segmental lesions (exhibiting at least one of the following: necrosis, proliferation, or hyalinosis) were enumerated. The percentage of damaged tubules (exhibiting at least one of the following: dilation, atrophy, or necrosis) was determined by scoring 400 renal cortical tubules per kidney in randomly selected microscopic fields $(\times 400)$.

Antibodies. The following primary antibodies were used for immunostaining: rat anti-mouse CD4 IgG2a clone RM4.5 (PharMingen, San Diego, California, USA), to detect CD4 T cells; rat anti-mouse CD8a (Ly-2) IgG2a clone 53-6.7 (PharMingen), to detect CD8 T cells; and rat anti-mouse macrophage IgG2b (prepared from F4/80 hybridoma supernatant HB198; American Type Culture Collection, Rockville, Maryland, USA), to detect macrophages. Rat anti-mouse IL-15 IgG2a clone M49 (Immunex Corp.) was used to detect IL-15 in the kidney. The negative isotype control antibodies were rat IgG2a clone R35-96 and rat IgG2b clone R35-38 (PharMingen).

IL-15 immunostaining. To detect IL-15, formalin-fixed tissue sections were deparaffinized and treated in the microwave in $0.01 \mathrm{M}$ sodium citrate buffer. Sections were incubated with $5 \%$ nonfat milk for 30 minutes. Endogenous peroxidase was blocked with $0.6 \% \mathrm{H}_{2} \mathrm{O}_{2}$. After digestion (with $1 \mathrm{mg} / \mathrm{ml}$ bovine testicular hyaluronidase in acetate buffer, $\mathrm{pH}$ 5.2, for 1 hour), sections were consecutively treated with avidin and biotin solutions. The sections were incubated with primary anti-mouse IL-15 antibody $(1: 1,000)$, then with biotinconjugated rabbit anti-rat IgG, and subsequently with biotin-conjugated goat anti-rabbit IgG. Positive signals were detected with an avidin-biotin-peroxidase system (Vector Laboratories Inc., Burlingame, California, USA). To examine the specificity of staining, primary antibody was incubated with a $100 \mathrm{M}$ excess of recombinant mouse IL-15 (Research Diagnostics Inc., Flanders, New Jersey, USA). After centrifugation, the supernatant (which no longer contained IL-15 antibody) was used as a negative control .

Identifying kidney-infiltrating leukocytes by immunostaining. Kidney-infiltrating T cells (CD4 and CD8) and macrophages were detected as previously described (15). Intraglomerular infiltrating cells were counted in 20 glomeruli per section. Interstitial cell infiltrates were evaluated by counting the number of leukocytes in the interstitium in ten randomly selected microscopic fields $\left(100 \mu \mathrm{m}^{2}\right)$ per kidney.

Ig in kidneys, and serum anti-sheep Ig isotypes. Cryosections of $I L-15^{+/+}$and $I L-15^{-/-}$kidneys $(4 \mu \mathrm{m})$ were transferred to Superfrost Plus slides (Fisher Scientific Co., Pittsburgh, Pennsylvania, USA), washed with cold PBS, blocked with $1 \%$ BSA in PBS, and stained at 1:800 with 
CY3-conjugated donkey anti-mouse IgG (AP129C; Sigma-Aldrich, St. Louis, Missouri, USA). The sections were examined by epifluorescent microscopy using a Nikon 40× Plan APO oil-immersion lens. The images were captured with a Spot CCD camera (Diagnostic Instruments Inc., Sterling Heights, Michigan, USA) and exported into Adobe Photoshop. Exposed settings were kept constant. Fluorescence intensity was measured by outlining the perimeter of five glomeruli per section and reading the luminosity from the Histogram command in the pull-down Image menu in Adobe Photoshop. Calibration of the CCD exposure time assured that the settings were in the linear range and well below saturation.

Serum anti-sheep Ig isotypes were measured as previously described (14).

Apoptotic cells in kidneys. Apoptotic cells in the kidneys were identified by the TUNEL method using a TdTFragEL DNA Fragmentation Detection Kit (Oncogene Research Products, Boston, Massachusetts, USA) according to the manufacturer's protocol. The apoptotic TECs were counted in 25 randomly selected renal cortical areas $\left(100 \mu \mathrm{m}^{2}\right)$ per kidney.

Cell death in cultured TECs. TECs were derived from the kidneys of mice without induced NSN $I L-15^{-/-}$and $I L-15^{+/+}$mice and grown on 96-well flat-bottom tissue culture plates (Corning-Costar Corp., Cambridge, Massachusetts, USA) at $1.0 \times 10^{4}$ cells/well as previously reported (16). To induce apoptosis, TECs were incubated in DMEM $/ 0.5 \%$ FCS with or without $0.05 \mu \mathrm{g} / \mathrm{ml}$ actinomycin D (AD) (Sigma Chemical Co.) for 24 hours. Alternatively, TECs were incubated in DMEM/0.5\% FCS with $5 \mu \mathrm{g} / \mathrm{ml}$ LPS and $100 \mathrm{U} / \mathrm{ml} \mathrm{IFN}-\gamma$ for 24 hours and then incubated in DMEM $/ 0.5 \%$ FCS containing 5 $\mu \mathrm{g} / \mathrm{ml} \mathrm{LPS}, 100 \mathrm{U} / \mathrm{ml} \mathrm{IFN}-\gamma, 1 \mu \mathrm{g} / \mathrm{ml}$ protein G (Pierce Chemical Co., Rockford, Illinois, USA), and $1 \mu \mathrm{g} / \mathrm{ml}$ anti-Fas antibody (clone Jo2; PharMingen) for an additional 24 hours. TECs incubated in DMEM/0.5\% FCS containing $2.5 \mu \mathrm{g} / \mathrm{ml} \mathrm{LPS}$ and $100 \mathrm{U} / \mathrm{ml}$ IFN- $\gamma$ served as control. The TECs were stained with $0.1 \%$ crystal violet for 10 minutes. Nonadherent cells were removed by washing twice with ice-cold PBS, and the extinction of stained adherent TECs was measured at $600 \mathrm{~nm}$ in a Bio-Rad ELISA Reader (Bio-Rad Laboratories Inc., Hercules, California, USA). The data was reported as a percentage of cell death (OD adherent cells in medium alone minus OD adherent cells in medium plus cytokine)/(OD adherent cells in medium alone). To determine whether the increase in cell death in $I L-15^{-/-}$ TECs was specific, we blocked IL-15 in wild-type TECs with 100-200 ng/ml mouse soluble IL-15R (sIL-15R $\alpha$ ) or mouse soluble mutant IL-15R (smIL-15R $\alpha$ ), the nonbinding control (17). The optimal sIL-15R $\alpha$ concentration was based on the evidence that $100 \mathrm{ng} / \mathrm{ml}$ of sIL-15R $\alpha$ blocked bioactivity of $0.1 \mathrm{ng} / \mathrm{ml}$ IL- 15 in a CTLL2 cell line assay (11). To determine whether exogenous IL-15 protects $I L-15^{-/-}$TECs from death, we added mouse recombinant IL-15 (50 or $200 \mathrm{ng} / \mathrm{ml}$ ) (Research Diagnostics Inc.) to the medium.
Apoptosis in cultured TECs. Apoptosis in TECs after exposure to apoptotic stimuli (AD or anti-Fas antibody) was assessed using the TUNEL method. TECs derived from $I L-15^{-/-}$and $I L-15^{+/+}$mice were grown on 24-well tissue culture plates (Becton Dickinson and Co., Franklin Lakes, New Jersey, USA) at $10^{5}$ cells/well. After stimulation, floating and adherent cells were collected and fixed to glass slides using a Cytospin cytocentrifuge (Shandon Inc., Pittsburgh, Pennsylvania, USA). These TECs were fixed with $4 \%$ paraformaldehyde, and apoptotic cells were identified by TUNEL staining using a TdT-FragEL DNA Fragmentation Detection Kit (Oncogene Research Products) according to the manufacturer's protocol.

RT-PCR analysis of IL-15 and IL-15Rs. Total RNA from the renal cortex, or primary cultured cells were prepared for RT-PCR (18). PCR for IL-15, IL-15R $\alpha$ chain, IL-2R $\beta$ chain, and the common $\gamma$ chain was conducted with $1 \mu \mathrm{l}$ of cDNA in a total volume of $50 \mu \mathrm{l}$ containing $20 \mathrm{pmol}$ of each primer, $10 \mathrm{mM}$ Tris- $\mathrm{HCl}$ at $\mathrm{pH}$ 8.3, $50 \mathrm{mM} \mathrm{KCl}, 1.5 \mathrm{mM} \mathrm{MgCl} 2,0.2 \mathrm{mM}$ dNTPs, and 2.5 U Taq polymerase (Promega Corp., Madison, Wisconsin, USA). Primer sequences were as follows. IL-15: sense, 5'-GCAGAGTTGGACGAAGAC-3'; antisense, 5'-AGCACGAGATGGATGTATT-3'. IL-15R $\alpha$ chain: sense, $5^{\prime}$-TCTCCCCACAGTTCCAAAAT- $3^{\prime}$; antisense, $5^{\prime}$-GGCACCCAGGCTCAGTAAAA-3'. IL-2R $\beta$ chain: sense, $5^{\prime}$-GGTTGGCGTAGGGTAAAG AC-3'; antisense, $5^{\prime}$-AGCGGACAGGCGAGGAGAGC-3'; common $\gamma$ chain: sense, $5^{\prime}$-СТССТАСТCTGCСССТTCCA-3'; antisense, $5^{\prime}$-TCCATTTACTCCACTGTTGA-3'.
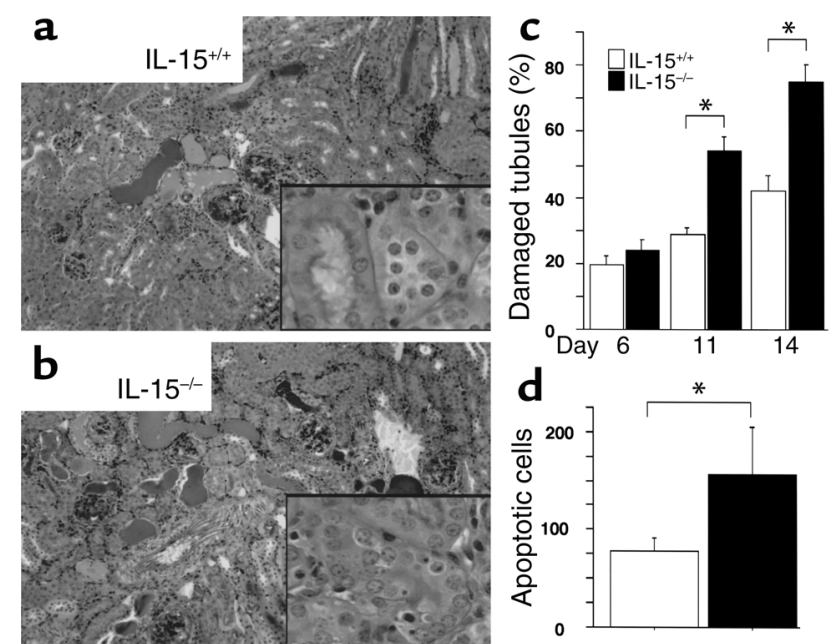

\section{Figure 1}

Tubular pathology and apoptosis are markedly increased in $I L-15^{-/-}$kidneys during NSN. Tubular damage is increased in $I L-15^{-/-}$kidneys (a) compared with $/ L-15^{+/+}$kidneys (b) with NSN measured on day 11 after induction (inset; arrow indicates damaged tubule). Tubular damage (c), and apoptosis (d) (measured on day 11 by TUNEL assay) are increased during NSN in $/ L-15^{-/-}$ kidneys. Data were analyzed by Student $t$ test and are presented as mean \pm SEM. $n=8$ per group. ${ }^{*} P<0.05$. Magnification: $a$ and b, $\times 100$; insets, $\times 400$. 


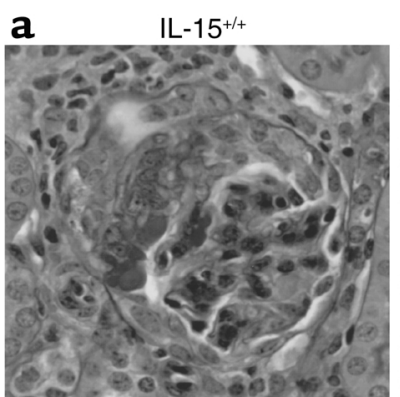

b $\quad \mathrm{LL}-15^{-1-}$

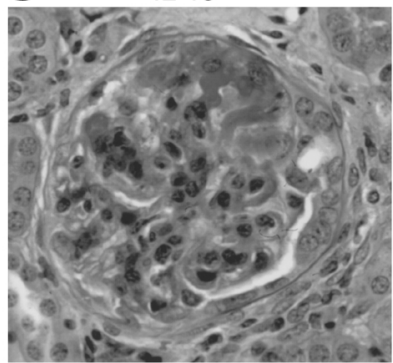

C

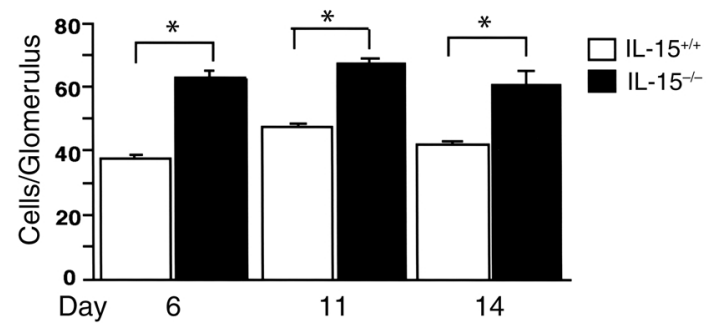

Quantitating intrarenal cytokine $m R N A$ using real-time PCR. MCP-1, RANTES, CSF-1, IFN- $\gamma$, or IL-12 (p40) in the renal cortex were analyzed using real-time twostep quantitative RT-PCR. Relative quantitation was performed with SYBR Green PCR reagents (QIAGEN Inc., Valencia, California, USA) and an ABI PRISM 7700 Sequence Detection System (PE Applied Biosystems, Foster City, California, USA) according to both manufacturers' instructions. Reactions were performed using $100 \mathrm{ng}$ of cDNA. The PCR consisted of HotStarTaq activation for 15 minutes at $95^{\circ} \mathrm{C}$, followed by 40 cycles with heating to $95^{\circ} \mathrm{C}$ for $15 \mathrm{sec}$ onds and cooling to $60^{\circ} \mathrm{C}$ for 1 minute. The mRNA levels were normalized to GAPDH. Sequence-specific PCR primers were purchased from Invitrogen Corp. (Carlsbad, California, USA). The PCR primers used were as follows. GAPDH: sense, 5'-CATGGCCTCCAAGGAGTAAG-3'; antisense, $5^{\prime}$-CCTAGGCCCCTCCTGTTATT- $3^{\prime}$. MCP-1: sense, $5^{\prime}$-ACCAGCAAGATGATCCCAAT- ${ }^{\prime}$; antisense, $5^{\prime}$-TGTCTGGACCCATTCCTTCT$3^{\prime}$. RANTES: sense, $5^{\prime}$-TGCCAACCCAGAGAAGAAGT$3^{\prime}$; antisense, 5'-AAGCTGGCTAGGACTAGAGCAA-3'. CSF-1: sense, $5^{\prime}$-ACCTGGCAAGGGACTCACTA-3'; antisense, $5^{\prime}$-CAGGCTCTCTTCTTGGGAAA- $3^{\prime}$. IFN- $\gamma$ : sense, $5^{\prime}$-AGCTCTTCCTCATGGCTGTT- $3^{\prime}$; antisense, $5^{\prime}$-TTTTGCCAGTTCCTCCAGAT- $3^{\prime}$. IL-12 (p40): sense, $5^{\prime}$-GACCAAACCAGCACATTGAA- $3^{\prime}$; antisense, $5^{\prime}$-CTACCAAGGCACAGGGTCAT-3'.

\section{Results}

Renal tubular pathology is markedly increased, while glomerular pathology is modestly worse and BUN is elevated in $I L-15^{-1}$ mice during NSN. To investigate the importance of IL-15 in kidneys undergoing immune injury, we induced NSN in $I L-15^{-/-}$and $I L-15^{+/+}$mice. Unexpectedly, we detected a striking increase in renal pathology in the $I L-15^{-/-}$mice compared with $I L-15^{+/+}$mice; this was most notable in the tubules on day 11 (Figure 1, a-c). Tubular damage

\section{Figure 2}

The number of cells in glomeruli is modestly increased in $1 \mathrm{L-15^{-/ } -}$ kidneys. We detected an increase in cell/glomerulus at days 6,11 , and 14 in $1 \mathrm{~L}-15^{-/-}$glomeruli (a and c) compared with $\mathrm{IL-15^{+/+ }}$ glomeruli ( $\mathbf{b}$ and $\mathbf{c}$ ) after induction of NSN. Magnification: $\mathbf{a}$ and $\mathbf{b}$, $\times 100$. Cells in glomeruli were counted in sections stained with periodic acid-Schiff reagent ( 50 glomeruli/kidney, $\times 400$ ). Data were analyzed by Student $t$ test and are presented as mean \pm SEM. $n=8$ per group. ${ }^{*} P<0.05$.

(which included one or more of the following: dilation with flattened or degraded epithelium, atrophy, thickening, and rupture of basement membranes) was increased in $I L-15^{-/-}$mice on days 11 and 14 (Figure 1, b and c) compared with $I L-15^{+/+}$mice (Figure 1 , a and c). In addition, peritubular leukocytic infiltrates and casts in tubule lumens were associated with damaged tubules (Figure 1, a and b). The change in glomerular pathology was subtler. We noted an increase in cell number of $30-40 \%$ within glomeruli in $I L-15^{-/-}$mice compared with glomeruli in wild-type mice at 6,11 , and 14 days (Figure 2). On the other hand, we did not detect a difference in the number of glomerular crescents.

Accompanying the increased renal pathology in the $I L-15^{-/}$mice was a greater loss of renal function. BUN levels measured on days 11 and 14 after initiation of NSN were elevated in the $I L-15^{-/-}$mice compared with wild-type mice (Figure 3 ). Urine protein levels in $I L-15^{+/+}$and $I L-15^{-/-}$mice were increased to a similar degree on days 5 and 13 after NSN induction (data not shown). However, urinary protein is not a suitable functional marker of tubulointerstitial injury in this model, because nephrotoxic serum reacts with several podocyte surface antigens and causes proteinuria by direct podocyte injury in the absence of an inflammatory response (19).

Apoptotic cells are increased in $I L-15^{-/-}$mice during NSN. The increase in tubular injury in $I L-15^{-/-}$compared with IL-15 $5^{+/+}$mice during NSN indicated that IL-15 might be an epithelial cell survival factor. To address this issue, we

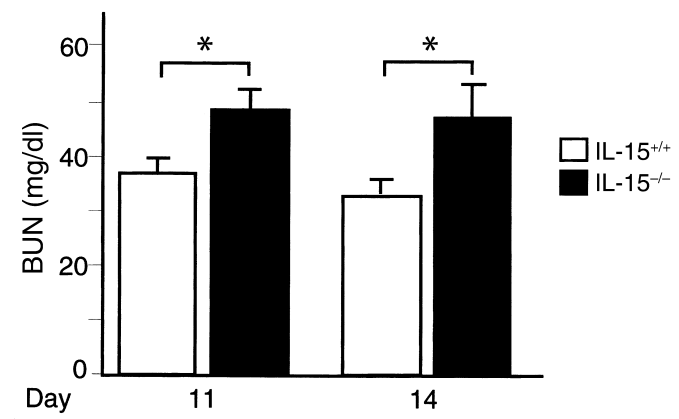

Figure 3

BUN is higher in $/ L-15^{-/-}$mice with NSN than in wild-type mice with NSN. Measurements were taken on day 11 and day 14 after induction of NSN and results were analyzed by ANOVA with replication. Data are presented as mean \pm SEM. The BUN of these mice prior to receiving nephrotoxic serum was $33.7 \pm 1.5 \mathrm{mg} / \mathrm{dl} . n=4$ per group. ${ }^{*} P=0.014$. 


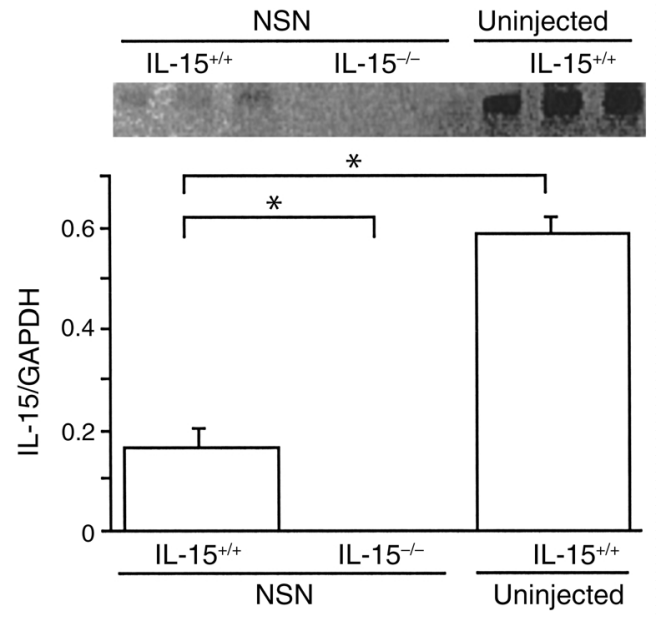

\section{Figure 4}

IL-15 transcription is downregulated in the kidneys of mice with NSN. There is a decrease in IL-15 transcript in the kidneys of $I L-15^{+/+}$ mice injected with nephrotoxic serum (measured on day 14 after induction of NSN) compared with transcript in kidneys of uninjected $/ L-15^{+/+}$mice, as measured by RT-PCR. Data were analyzed by Bonferroni-Dunn test and are presented as mean \pm SEM. $n=3$ per group. ${ }^{*} P<0.05$.

enumerated the number of apoptotic cells in the kidney. Apoptotic cells in the kidney were almost exclusively within cortical tubules; $I L-15^{-/-}$kidneys had twice as many apoptotic cells as did $I L-15^{+/+}$kidneys (Figure $1 \mathrm{~d}$ ). IL-15 expression in the kidney is decreased after the induction of NSN. The increased renal pathology in $I L-15^{-/-}$ mice prompted us to probe for the intrarenal expression of IL-15 in wild-type mice with NSN. As opposed to most cytokines and chemokines, which are not constitutively expressed, we detected an abundant expression of IL-15 in kidneys prior to NSN. This IL-15 expression decreased dramatically (threefold) on day 14 of NSN (Figure 4). Intrarenal IL-15 was detected by immunostaining. In agreement with the IL-15 transcripts, IL-15 protein was prominent in untreated wildtype kidneys without NSN. We detected IL-15 mainly in tubules (Figure 5a), with lesser amounts in glomeruli (Figure $5 \mathrm{~b}$ ) and vascular endothelium in the normal kidneys. However, during NSN, IL-15 measured on day 14 was markedly reduced in the tubules (Figure 5c) and glomeruli (Figure 5d) of

\section{Figure 5}

IL-15 protein is decreased in tubules and glomeruli during NSN in wild-type mice. IL-15 was strongly expressed in the tubules (arrows) and glomeruli (arrowheads) in normal kidneys (a and b). IL-15 expression was markedly decreased within tubules and glomeruli during NSN (day 14) (c and d). Magnifications: $\mathbf{a}$ and $\mathbf{c}, \times 100 ; \mathbf{b}$ and $\mathbf{d}, \times 400$.
IL-15 $15^{+/}$mice. Sections stained for IL-15 with IL-15 antibody that was preabsorbed with an excess amount of mouse rIL-15 were negative, confirming specificity (not shown). Based on the abundant expression of IL-15 in normal TECs that decreases during NSN, and the enhanced TEC pathology and apoptosis in $I L-15^{-/-}$kidneys during NSN, we hypothesized that IL-15 is a survival factor for epithelial cells.

IL-15 protects TECs from AD-induced death and apoptosis. To test the hypothesis that IL-15 is a survival factor for TECs, we determined whether AD-induced cell death was enhanced in $I L-15^{-/-}$TECs. We incubated primary cultured TECs derived from $I L-15^{+/+}$and $I L-15^{-/-}$mice with $\mathrm{AD}(0.05 \mu \mathrm{g} / \mathrm{ml}$ and $0.1 \mu \mathrm{g} / \mathrm{ml})$ for 24 hours. $I L-15^{-1-}$ TECs were more vulnerable to AD-induced cell death than $I L-15^{+/+}$TECs were (Figure 6a). We incubated the $I L-15^{+/+}$TECs with soluble IL-15R $\alpha$ (sIL-15R $\alpha$; $200 \mathrm{ng} / \mathrm{ml}$ ), a molecule that competitively blocks the binding of IL-15 to IL-15R $\alpha$, to determine whether enhanced TEC survival was specific to IL-15. The soluble mutant IL-15R, smIL-15R $\alpha(200 \mathrm{ng} / \mathrm{ml})$, which does not block the binding of IL-15 to IL-15R $\alpha$, served as a control. The sIL-15R $\alpha$ increased cell death in $I L-15^{+/+}$ TECs, while the smIL-15R $\alpha$ did not alter $I L-15^{+/+}$TEC survival (Figure 6b).

To determine whether IL-15 is anti-apoptotic, we exposed $I L-15^{-/-}$and $I L-15^{+/+}$TECs to AD as above and evaluated apoptosis by the TUNEL assay. IL-15-/TECs had an increase (56\%) in apoptosis compared with $I L-15^{+/+}$TECs (Figure 6c). Blocking the IL-15R on $I L-15^{+/+}$TECs exposed to AD with sIL-15R $\alpha$ increased apoptosis compared with $I L-15^{+/+}$TECs exposed to smIL-15R $\alpha$, the control molecule (Figure 6c). Blockade of IL-15R on $I L-15^{+/+}$TECs resulted in an amount of AD-induced apoptosis that was similar to that in $I L-15^{-/-}$TECs (Figure 6c). Furthermore, adding rIL-15 $(50 \mathrm{ng} / \mathrm{ml}$ and $200 \mathrm{ng} / \mathrm{ml})$ dramatically reduced AD-induced apoptosis of $I L-15^{-/-}$TECs. Taken together, these results indicate that IL-15 protects TECs from $\mathrm{AD}$-induced apoptosis.
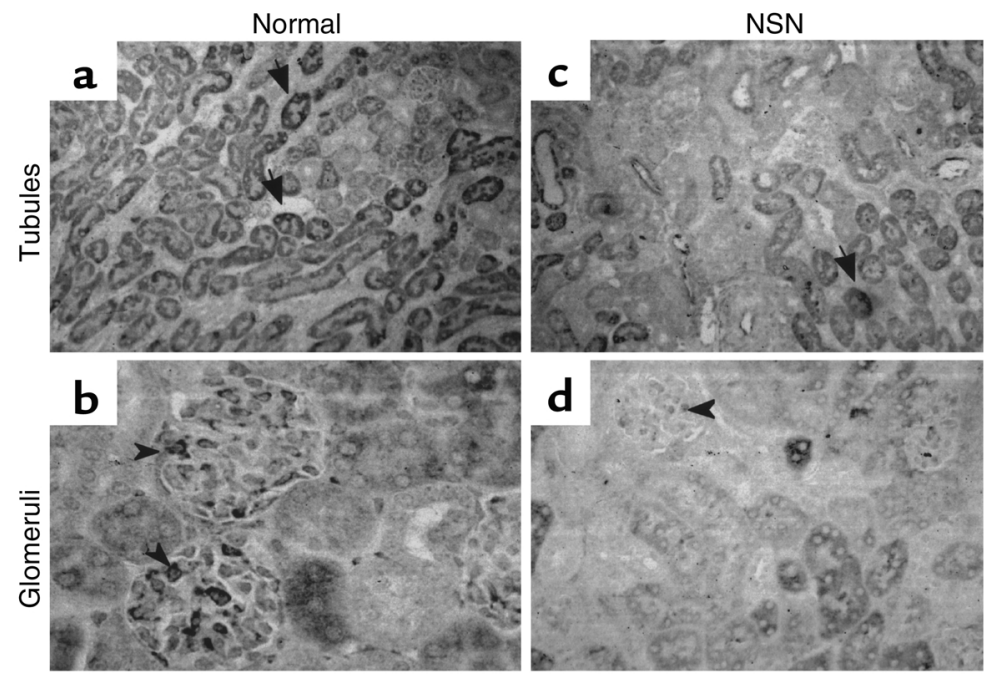

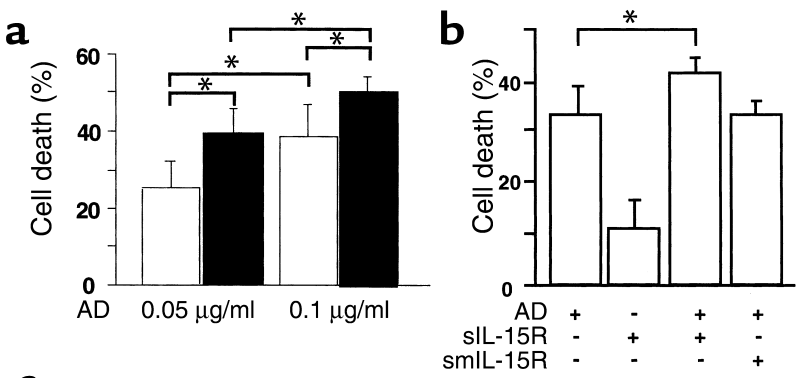

C

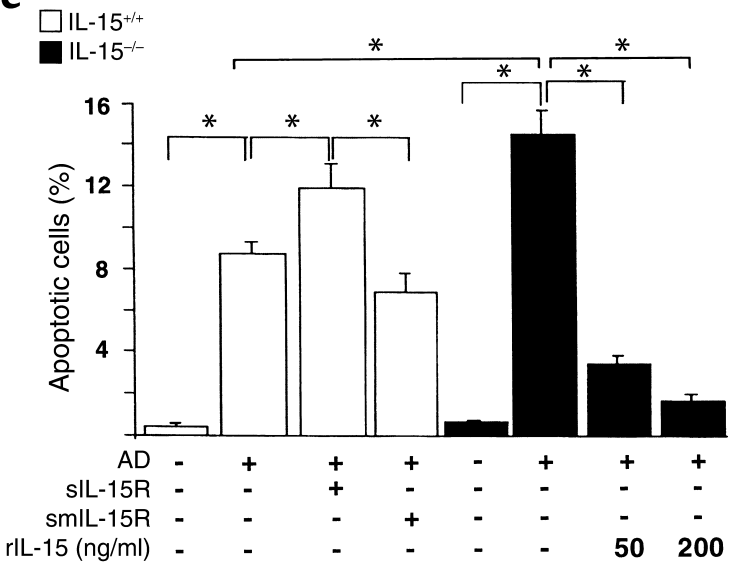

\section{Figure 6}

Cultured $I L-15^{-/-}$TECs are more susceptible to AD-induced cell death and apoptosis. AD causes a concentration-dependent increase in the number of dead cells that is more severe in $I L-15^{-/-}$TECs (a). Blocking IL-15 signaling with soluble receptor $(\mathrm{sIL}-15 \mathrm{R} \alpha)$ in $1 \mathrm{~L}-15^{+/+}$TECs increased AD-induced cell death (b). Blocking IL-15 with sIL-15R $\alpha$ increased $A D$-induced apoptosis in $I L-15^{+/+}$TECs, and exogenous rIL-15 protected IL-15- $/-$ TECs from AD-induced apoptosis (c). In comparison, adding smIL-15R did not alter findings ( $\mathbf{b}$ and $\mathbf{c}$ ). Data (presented as mean \pm SEM) were analyzed by the Fisher $t$ test ( $\mathbf{a}$ and b) and the Bonferroni-Dunn test (c) and are representative of three experiments using TECs isolated from different mice $(n=5)$. ${ }^{*} P<0.05$.

IL-15 protects TECs from Fas-induced cell death and apoptosis. To eliminate the possibility that IL-15 is a survival factor unique to $\mathrm{AD}$-induced TEC death, we explored the importance of IL-15 in Fas-mediated TEC death. We primed TECs with LPS and IFN- $\gamma$ to induce Fas expression on TECs, and then incubated the TECs with antiFas antibody and protein $\mathrm{G}$ to initiate Fas-induced cell death. Fas-induced TEC death was more pronounced (twofold) in $I L-15^{-/-}$TECs than in $I L-15^{+/+}$TECs and was diminished by the addition of rIL-15 (Figure 7a). As in AD-induced cell death, sIL-15R $\alpha(200 \mathrm{ng} / \mathrm{ml})$, but not smIL-15R $\alpha$, increased death of $I L-15^{+/+}$TECs to the level of $I L-15^{-/-}$TEC death (Figure $7 \mathrm{~b}$ ). In addition, we determined that $I L-15^{-1-}$ TECs had an increase in Fas-induced apoptosis that was more than $I L-15^{+/+}$TECs (Figure 7c). Moreover, adding rIL-15 $(200 \mathrm{ng} / \mathrm{ml})$ reduced TEC apoptosis in $I L-15^{-/-}$TECs to the level detected in IL-15-/- TECs (Figure 7c). Thus, IL-15 is a survival factor for Fas- and AD-induced TEC apoptosis.

IL-15 and IL-15R are expressed by normal TECs. To determine whether IL-15 could act as an autocrine molecule, we probed kidneys and primary TECs from normal
C57BL/6 mice for IL-15 and IL-15R expression. IL-15 transcripts were detected in the normal kidneys and TECs using RT-PCR (Figure 8a). The transcripts of the IL-15R, comprised of the IL-15R $\alpha$, IL-2R $\beta$, and common $\gamma$ chains, were identified in TECs (Figure 8b). Therefore, normal TECs express both IL-15 and all three chains of IL-15R.

Renal interstitial leukocytic infiltrates are more prominent in IL-15-/- mice during NSN. Leukocytic infiltrates in the renal interstitium are prominent in NSN (see Figure 9). In the IL-15/- kidneys during NSN, we detected an initial (on day 6 and day 11) enhanced increase in macrophages, and a more enduring increase in CD4 T cells measured on days 6,11 , and 14 in the interstitium versus wild-type kidneys (Figure 9, a and b) In contrast, CD8 $\mathrm{T}$ cells increased in $\mathrm{IL}-15^{+/+}$kidneys but not in IL-15 $15^{-/}$kidneys compared with pre-NSN levels (measured on day 6, day 11, and day 14; Figure 9c).

Glomerular lenkocytic infiltrates are increased in $I L-15^{-/-}$ kidneys. To determine whether leukocytes were responsible for increasing the numbers of cells in glomeruli, we stained for the presence of macrophages, CD4 T cells, and CD8 $\mathrm{T}$ cells. Initially, we detected more macrophages (day 6) and CD4 T cells (days 6 and 11) in IL-15 $15^{-/}$glomeruli than in $I L-15^{+/+}$glomeruli (Figure 10, $\mathrm{a}$ and $\mathrm{b}$ ). In contrast, as in the renal interstitium, the
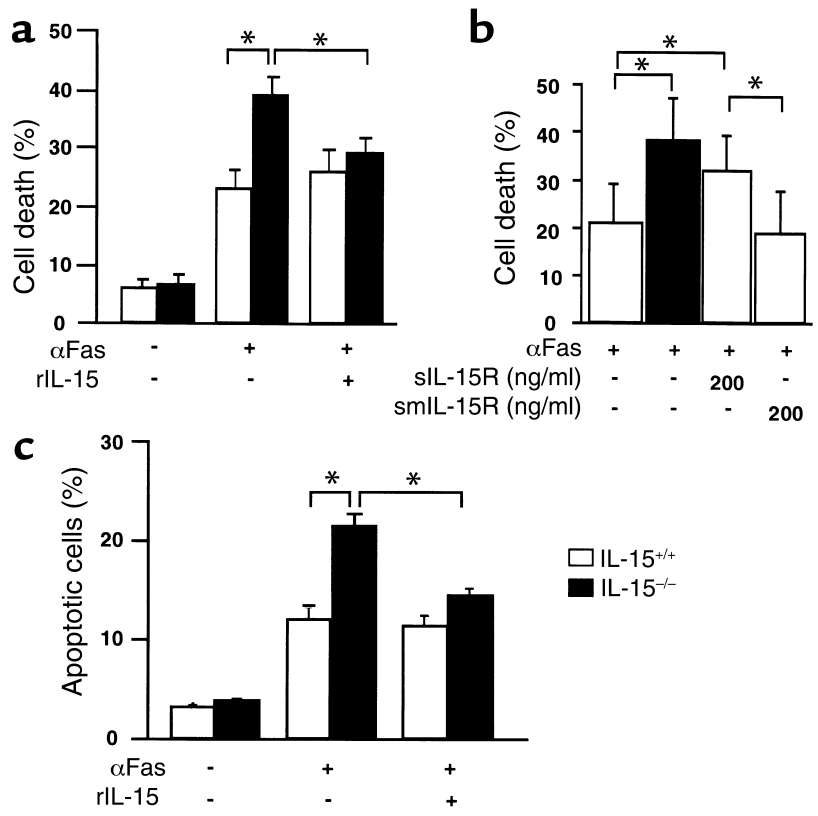

\section{Figure 7}

IL-15 protects TECs from Fas-induced cell death and apoptosis. (a) Adding rIL-15 reduced TEC death in $I L-15^{-/-}$TECs but not in $I L-15^{+/+}$ TECs ( $n=6$ per group). (b) Blocking IL-15 with sIL-15R $\alpha$ induced an increase in cell death in $1 \mathrm{~L}-15^{+/+}$TECs, while the mutant sIL-15R $\alpha$ molecule had no effect ( $n=3$ per group). (c) Fas-mediated apoptosis (measured by TUNEL assay) was increased in $I L-15^{-/-}$TECs compared with $I L-15^{+/+}$TECs. Adding rIL-15 reduced $I L-15^{-/-}$TEC apoptosis to $\mathrm{IL}-15^{+/+}$TEC levels ( $n=5$ per group). Data (presented as mean \pm SEM) were analyzed by the Bonferroni-Dunn test and are representative of more than three experiments using TECs isolated from different mice. ${ }^{*} P<0.05$. 


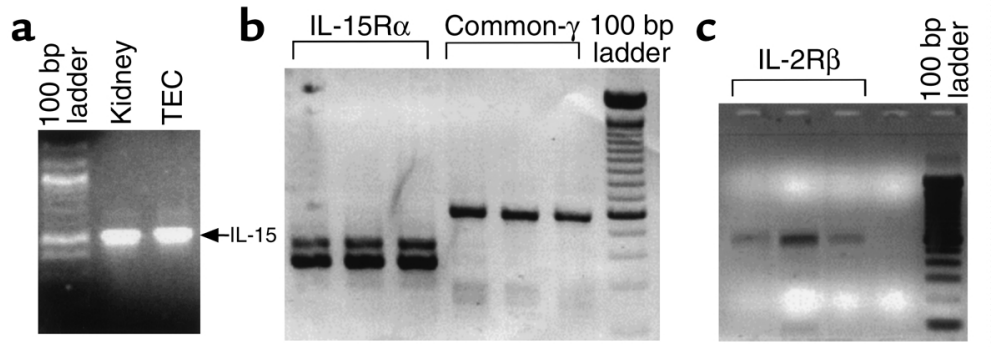

Figure 8

IL-15 and IL-15R mRNA is expressed in normal TECs. (a) Normal kidney and TECs express IL-15. (b) Normal TECs express the IL-15R $\alpha, \beta$, and common $\gamma$ chains. IL-15R transcripts were detected in TECs derived from three different mice. The data are representative of more than ten experiments.

numbers of CD8 $\mathrm{T}$ cells in $I L-15^{-/-}$glomeruli remained normal, while there was an increase in CD8 T cells in $I L-15^{+/+}$glomeruli (days 6, 11, and 14; Figure 10c). Taken together, this data indicates that macrophages and CD4 T cells are responsible, in part, for the increase in glomerular cells in $I L-15^{-/}$during NSN.

IL-15 inhibits intrarenal MCP-1 expression during NSN. We have previously reported that MCP-1, CSF-1, and RANTES recruit macrophages and $\mathrm{T}$ cells into the kidney $(15,18,20,21)$. In addition, we established that IFN- $\gamma$ and IL-12 are nephritogenic $(16,22)$. During NSN, MCP-1, CSF-1 and RANTES transcripts were increased in the renal cortex in $I L-15^{-/-}$and $I L-15^{+/+}$mice compared with normal mice (day 11; Figure 11). However, only MCP-1 was greater in the $I L-15^{-/-}$kidneys compared with the $I L-15^{+/+}$kidneys. Thus, IL-15 inhibits intrarenal MCP-1, and in turn may be responsible for dampening the influx of macrophages and T cells during NSN.

IL-15- mice do not have an increase in circulating anti-sheep Ig isotypes, or IgG in the kidney during NSN. We evaluated serum Ig isotypes in $I L-15^{-/-}$and wild-type mice during NSN on day 11 and day 14. Although there is a consistent trend to lower serum isotype titres on day 14 in $I L-15^{-/-}$mice, these values were not statistically significant. The $\mathrm{OD}_{450}$ readings were: $\mathrm{IgG}$, $1.0 \pm 0.1$ and $0.8 \pm 0.1 ; \operatorname{IgG} 1,1.1 \pm 0.1$ and $0.7 \pm 0.1$; IgG2a, $0.4 \pm 0.1$ and $0.2 \pm 0.1$, for $I L-15^{-/-}(n=5)$ and wild type $(n=6)$, respectively. The serum isotype findings in $I L-15^{-/-}$and wild-type mice at day 11 were similar to those of day 14 with the exception that total IgG levels were statistically decreased in the $I L-15^{-/-}$mice $(P<0.03)$. Taken together, this data suggests that the increased renal disease in $I L-15^{-/-}$mice was not a result of an increase in serum Ig's or a result of immune deviation toward a Th1 phenotype. In fact, the tendency for the serum Ig isotypes to be decreased in $I L-15^{-/-}$mice would suggest that renal disease should have been less, and not greater, in $I L-15^{-/-}$mice during NSN.

To establish whether the deposition of IgG differed between $I L-15^{-/-}$and wild-type mice, we quantitatively evaluated the deposition of host (mouse) IgG in the $I L-15^{-/-}$kidneys on day 14 after the induction of NSN. The results revealed similar amounts of $\operatorname{IgG}$ in the $I L-15^{-/}$and wild-type kidneys $(12.09 \pm 1.18$ and $11.39 \pm 0.74$ luminosity units, respectively; $n=5$ per group; $P<0.6)$. Mouse IgG is located in the capillary walls of the glomeruli, and the distribution is similar in both groups. This indicates that the total amount of mouse anti-sheep IgG deposited in the glomeruli is not different in the two groups, and that the amount of antibody deposited in the kidney in $I L-15^{-/-}$mice was not influenced by the lack of IL-15.

\section{Discussion}

We now report that IL-15 counteracts renal injury in a $T$ cell-dependent disease akin to human kidney illnesses. This is the first report that: (a) IL-15 is a survival factor for kidney epithelial cells; (b) IL-15 is protective in a $\mathrm{T}$ cell-dependent disease; (c) IL-15 inhibits the induction of MCP-1 in vivo; and (d) IL-15 protects the kidney during nephritis. In addition, this data is particularly compelling since it was generated using a strain genetically deficient in IL-15.

Interstitial inflammation is a major determinant of the outcome of human renal disease $(23,24)$. Most

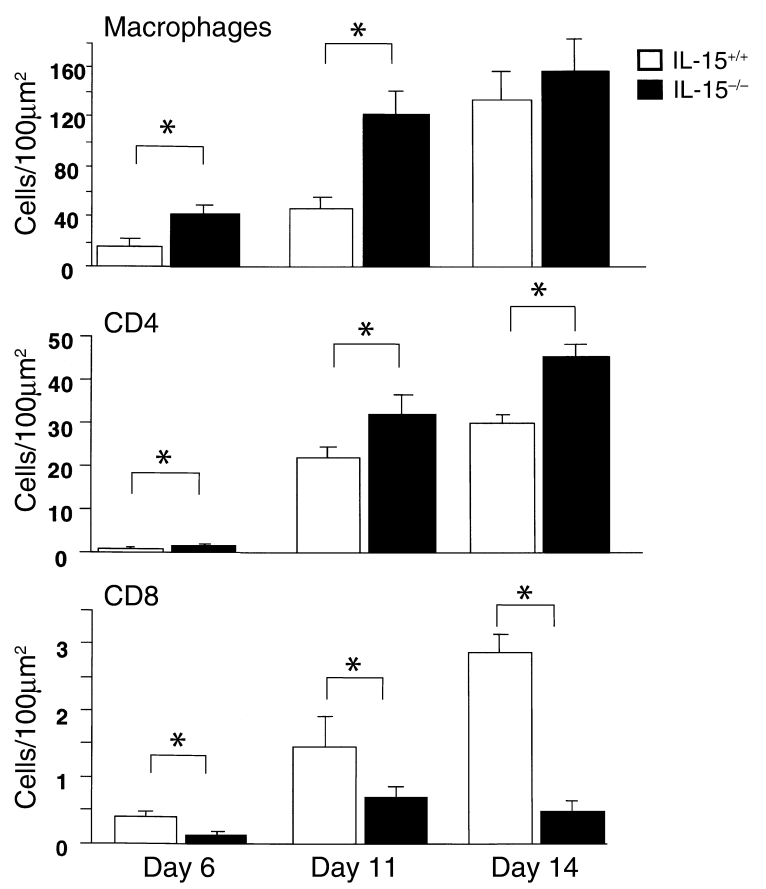

Figure 9

Interstitial CD4 T cells and macrophages are increased, while CD8 T cells are decreased in $I L-15^{-/-}$mice as compared with $I L-15^{+/+}$mice with NSN. Macrophages and CD4 T cells in the interstitium were markedly increased, while CD8 T cells were decreased in $/ \mathrm{L}-15^{-/-}$kidneys. Data (presented as mean \pm SEM) were analyzed by BonferroniDunn test. $n=5$ per group. ${ }^{*} P<0.05$. 

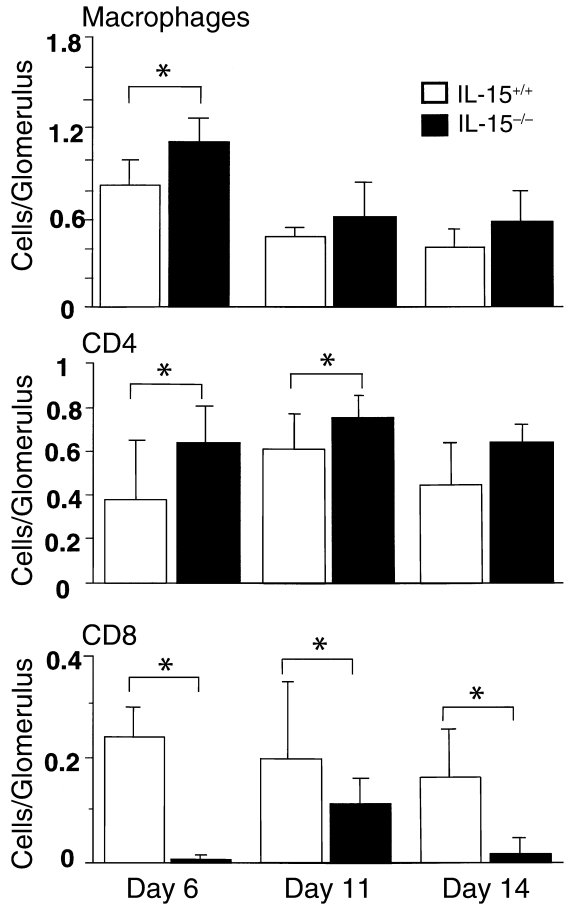

\section{Figure 10}

Glomerular macrophages and CD4 T cells are initially increased in IL-15 $5^{-/-}$mice with NSN. In contrast, CD8 T cells were substantially lower in glomeruli of $/ L-15^{-/-}$mice than in glomeruli of $/ L-15^{+/+}$mice. Data were evaluated by Bonferroni-Dunn test and are presented as mean \pm SEM. $n=8$ per group. ${ }^{*} P<0.01$.

cytokines are not expressed by normal kidneys, but are induced during inflammation $(18,25)$ and are largely expressed in TECs $(15,18,26,27)$. The interplay between the kidney-infiltrating leukocytes and the TECs determines the extent of interstitial inflammation $(28,29)$. An amplification cascade drives kidney disease: interstitial T cells release IFN- $\gamma$ which activates adjacent TECs $(15,18,30,31)$, which in turn release chemokines (MCP-1) and cytokines (CSF-1) that are responsible for recruiting macrophages and $\mathrm{T}$ cells (32). Subsequently, upon activation, macrophages release molecules that induce apoptosis in TECs (15). Since TEC apoptosis correlates with tubulointerstitial fibrosis, protecting the TECs from injury is critical in combating kidney disease (33).

We now report that intrarenal IL-15 inhibits TEC apoptosis. Typically, cytokines are not constitutively expressed in TECs, but rather are upregulated during renal disease $(30,31)$. IL-15 is atypical. It is constitutively and abundantly expressed in normal TECs and is reduced during renal injury, as shown in NSN and in spontaneous lupus nephritis in MRL-Fas ${ }^{l p r}$ mice (data not shown). Thus, IL-15 in normal TECs is well positioned to guard against unwanted immunologic insults.

Initially, IL-15 was identified as a survival factor in $\mathrm{T}$ cells. It is now clear that IL-15 is a survival factor for a broader array of cell types. IL-15 promotes cell survival in hematopoietic cells, including $\mathrm{T}$ cells (34),
B cells, mast cells (35), and neutrophils (36). The evidence that IL-15 is a survival factor for nonhematopoietic cells is far more limited. In vitro data supports the concept that IL-15 is anti-apoptotic in fibroblasts (37) and keratinocytes (38). Moreover, in vivo data is limited to suppression of apoptosis in hepatocytes using a long-acting IL-15 (IL-15-IgGb fusion protein) to inhibit anti-Fas-induced rapid hepatic failure (39). Thus, it is plausible that IL-15 is a general survival factor for epithelial cells.

The mechanism responsible for IL-15 counteracting TEC apoptosis is not known. We have established that TECs express all three chains of the IL-15R $(\alpha, \beta$, and $\gamma$ ). In a murine fibroblast cell line (L929), the binding of IL- 15 to IL-15R $\alpha$ competes with the TNFR1 complex for TRAF2 binding, impeding the assembly of key adapter proteins in the TNFR1 complex and in turn inducing I $\mathrm{K} B \alpha$ phosphorylation (37). Thus, it is possible that IL-15R $\alpha$ signaling of TECs may induce similar anti-apoptotic mechanisms. In addition, members of the $\mathrm{Bcl} 2$ protein family have been implicated as regulators of TEC cell death during acute renal failure (40). Since IL-15 induces Bcl- $\mathrm{x}_{\mathrm{L}}$ expression and prevents apoptosis in a mouse mast cell line,
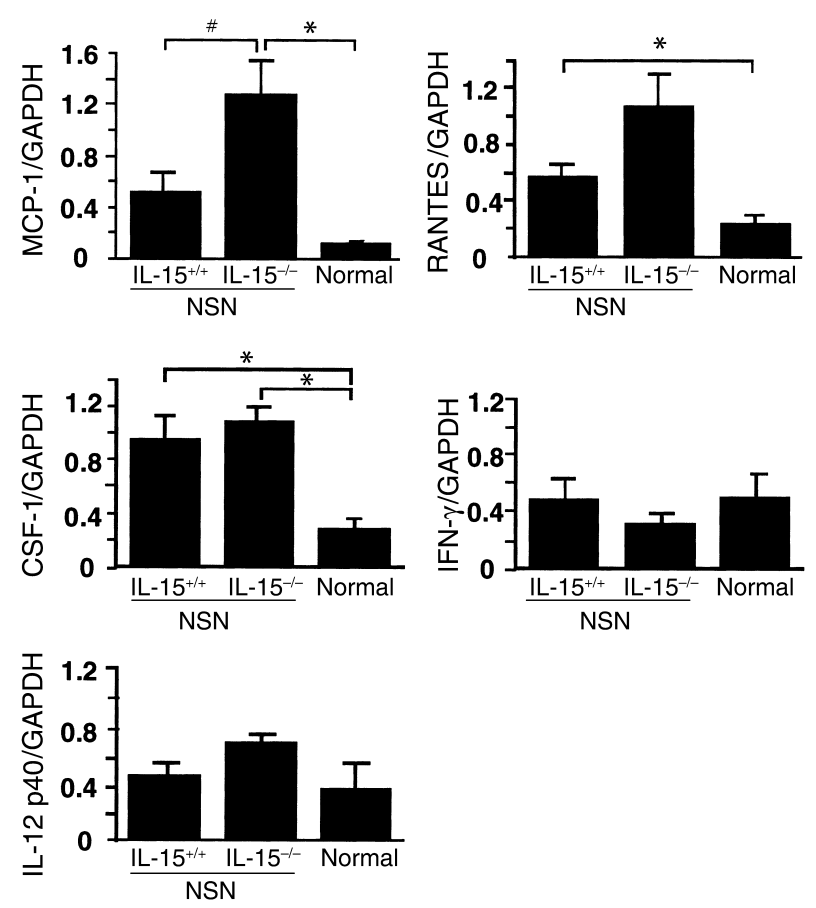

Figure 11

IL-15 inhibits MCP-1 expression during NSN. MCP-1, CSF-1, and RANTES transcripts, but not IL-12 ( $\mathrm{p} 40$ ) or IFN- $\gamma$, are upregulated in both $/ L-15^{-/-}$and $/ L-15^{+/+}$mice in the renal cortex during NSN. MCP-1 transcripts are further increased in $/ L-15^{-/-}$kidneys compared with $/ L-15^{+/+}$kidneys during NSN (day 11). Thus, IL-15 inhibits MCP-1 expression during NSN. Analysis was done by real-time PCR normalized to GAPDH expression. Data were analyzed by Bonferroni-Dunn test and are presented as mean \pm SEM. $n=3$ per group. ${ }^{*} P<0.05$ versus normal; $\# P<0.05$ versus $I L-15^{+/+}$. Normal, wild-type mice without induced NSN. 
it is possible that IL-15 induces Bcl- $\mathrm{x}_{\mathrm{L}}$ in TECs (41). We are investigating the precise IL-15-mediated antiapoptotic pathways in TECs.

Although there is a substantial increase in TEC apoptosis in $I L-15^{-/-}$mice, many cells survive. Thus, IL-15 is not the only TEC survival factor. Osteopontin, a secreted phosphoprotein expressed by TECs, protects TECs from apoptosis (42). However, unlike IL-15, osteopontin is a macrophage chemoattractant, and therefore contributes to nephritis. We are probing for the other TEC survival factors that combat renal disease.

It is intriguing that despite the absence of the $\mathrm{T}$ cell growth factor IL-15, there is a marked increase in CD4 $T$ cells and macrophages in the renal interstitium, and a subtler increase in these leukocytes in glomeruli during NSN. This suggests that the action of IL-15 as a survival factor for epithelial cells and an inhibitor of MCP-1 has a greater impact on the pathogenesis of renal disease than does IL-15's role in promoting the expansion of T cells. Moreover, this data indicates that IL-15 is not required to drive the expansion of CD4 T cells in kidney diseases, and suggests that the $\mathrm{T}$ cell growth factor IL-2 is sufficient for this process. IL-15-deficient mice have a pronounced reduction in CD8 T cells and NK cells (3). During NSN, few CD8 T cells accumulate in the kidney or in the spleen (data not shown) in the IL-15-deficient strain. By extension, we suggest that CD8 $\mathrm{T}$ cells are not instrumental in promoting some $\mathrm{T}$ cell-dependent renal diseases.

It is noteworthy that tubular injury and TEC apoptosis were more severe in $I L 15^{-/-}$mice than in wild-type mice in our study, despite a similar amount of proteinuria. This has several implications. First, there is a growing consensus that proteinuria is an important factor in the development of tubular injury and consequent interstitial fibrosis (43). Although cytokines, chemokines, and growth factors have been implicated in the interstitial inflammation and postinflammatory fibrogenic reaction associated with proteinuria, less is known about the mechanisms by which proteinuria causes TEC damage. Complement, modified albumin, and other molecules have been implicated (43-45). Regardless of the mechanism, our results demonstrate that IL-15-deficient TECs are more susceptible to injury in NSN, and are more likely than are wild-type TECs to undergo apoptosis, despite equivalent amounts of proteinuria. In addition, since proteinuria is similar in the two groups, this would suggest that there is equivalent glomerular injury. However, this is at variance with the pathology and elevated BUN levels in the $I L 15^{-/-}$mice. To understand this apparent discrepancy, it is important to recognize the limitations of proteinuria as a marker of renal injury in this model. Nephrotoxic serum is capable of inducing proteinuria by binding to one or more podocyte antigens (19) or by recruiting inflammatory mediators. These include the proinflammatory and direct effects of complement (46, 47), leukocyte recruitment by Fc receptor binding (48), and, in animals presensitized to the heterologous Ig, a cell-mediated macrophage-dependent reaction (13). This dissociation between glomerular injury and proteinuria was further illustrated in P-selectin-deficient mice in which proteinuria was unaffected despite differences in glomerular leukocyte infiltration during the heterologous phase of NTN (49). Finally, tubular injury itself is able to reduce the glomerular filtration rate and raise BUN by altering tubular-glomerular feedback and thereby decreasing the number of functioning nephrons. Thus, we conclude that IL-15-deficient mice suffer from a greater loss of renal function than wildtype mice do because they are more susceptible to tubular damage despite similar levels of proteinuria.

Deleting a gene in advance of disease, and blockade of a molecule are often but not always similar. For example, a P-selectin deficiency exacerbates NSN (50), while blocking antibodies to P-selectin diminishes the acute phase of this disease (51). Since blockade of IL-15 protects against murine collagen arthritis, the generalized Shwartzman reaction, and delayed-type hypersensitivity, we plan to determine whether blocking IL-15 during NSN enhances or protects against renal injury $(10-12,52)$.

There are several mechanisms that may be responsible for enhanced apoptosis in $I L-15^{-/-}$TECs during NSN. MCP-1 plays a major pathogenic role in this model (15, 53). MCP-1 recruits macrophages into the interstitium, and activated macrophages induce TEC apoptosis (15). During NSN, MCP-1 is increased in $I L-15^{-/-}$kidneys compared with $I L-15^{+/+}$kidneys. This finding is consistent with IL-15 downregulating MCP-1 in a colonic epithelial cell line (54). Therefore, it is possible that an IL-15 deficiency leads to exaggerated TEC apoptosis for two reasons: anti-apoptotic molecules are not induced, and MCP-1 expression (and in turn, the increased interstitial macrophage infiltration) is not inhibited.

In conclusion, we suggest that provision of IL-15 in some human kidney diseases may be therapeutic.

\section{Acknowledgments}

This work was supported in part by a National Kidney Foundation grant to J. Hirahashi, and by NIH grants to V.R. Kelley (DK-36149, DK-56848, and DK-52369) and D.J. Salant (DK-30932 and HL-63894). We wish to acknowledge Surya M. Nauli for his assistance in preparation of this manuscript.

1. Grabstein, K.H., et al. 1994. Cloning of a T cell growth factor that interacts with the beta chain of the interleukin-2 receptor. Science. 264:965-968.

2. Weiler, M., et al. 1998. Interleukin-15, a leukocyte activator and growth factor, is produced by cortical tubular epithelial cells. J. Am. Soc. Nephrol. 9:1194-1201.

3. Kennedy, M.K., et al. 2000. Reversible defects in natural killer and memory CD8 T cell lineages in interleukin 15-deficient mice. J. Exp. Med. 191:771-780.

4. Giri, J.G., et al. 1995. Identification and cloning of a novel IL-15 binding protein that is structurally related to the alpha chain of the IL-2 receptor. EMBO J. 14:3654-3663.

5. Li, X.C., et al. 2001. IL-15 and IL-2: a matter of life and death for T cells in vivo. Nat. Med. 7:114-118.

6. Ku, C.C., Murakami, M., Sakamoto, A., Kappler, J., and Marrack, P. 2000. Control of homeostasis of CD8+ memory T cells by opposing cytokines. Science. 288:675-678. 
7. McInnes, I.B., et al. 1996. The role of interleukin-15 in T-cell migration and activation in rheumatoid arthritis. Nat. Med. 2:175-182.

8. Kirman, I., and Nielsen, O.H. 1996. Increased numbers of interleukin15-expressing cells in active ulcerative colitis. Am. J. Gastroenterol. 91:1789-1794.

9. Pavlakis, M., et al. 1996. Intragraft IL-15 transcripts are increased in human renal allograft rejection. Transplantation. 62:543-545.

10. Smith, X.G., et al. 2000. Selective blockade of IL-15 by soluble IL-15 receptor alpha-chain enhances cardiac allograft survival. J. Immunol. 165:3444-3450.

11. Ruchatz, H., Leung, B.P., Wei, X.Q., McInnes, I.B., and Liew, F.Y. 1998 Soluble IL-15 receptor alpha-chain administration prevents murine collagen-induced arthritis: a role for IL-15 in development of antigeninduced immunopathology. J. Immunol. 160:5654-5660.

12. Kim, Y.S., et al. 1998. Targeting the IL-15 receptor with an antagonist IL-15 mutant/Fc gamma2a protein blocks delayed-type hypersensitivity. J. Immunol. 160:5742-5748.

13. Holdsworth, S.R., Kitching, A.R., and Tipping, P.G. 1999. Th1 and Th2 Thelper cell subsets affect patterns of injury and outcomes in glomerulonephritis. Kidney Int. 55:1198-1216.

14. Topham, P.S., et al. 1999. Lack of chemokine receptor CCR1 enhances Th1 responses and glomerular injury during nephrotoxic nephritis. J. Clin. Invest. 104:1549-1557.

15. Tesch, G.H., et al. 1999. Monocyte chemoattractant protein-1 promotes macrophage-mediated tubular injury, but not glomerular injury, in nephrotoxic serum nephritis. J. Clin. Invest. 103:73-80.

16. Schwarting, A., Wada, T., Kinoshita, K., Tesch, G., and Kelley, V.R. 1998. IFN-gamma receptor signaling is essential for the initiation, acceleration, and destruction of autoimmune kidney disease in MRL-Fas(lpr) mice. J. Immunol. 161:494-503.

17. Wei, X., et al. 2001. The Sushi domain of soluble IL-15 receptor alpha is essential for binding IL-15 and inhibiting inflammatory and allogenic responses in vitro and in vivo. J. Immunol. 167:277-282.

18. Tesch, G.H., Maifert, S., Schwarting, A., Rollins, B.J., and Kelley, V.R. 1999. Monocyte chemoattractant protein 1-dependent leukocytic infiltrates are responsible for autoimmune disease in MRL-Fas $(\mathrm{lpr})$ mice. J. Exp. Med. 190:1813-1824.

19. Chugh, S., et al. 2001. Aminopeptidase A: a nephritogenic target antigen of nephrotoxic serum. Kidney Int. 59:601-613.

20. Moore, K.J., Wada, T., Barbee, S.D., and Kelley, V.R. 1998. Gene transfer of RANTES elicits autoimmune renal injury in MRL-Fas $(1 \mathrm{pr})$ mice. Kidney Int. 53:1631-1641.

21. Naito, T., et al. 1996. Macrophage growth factors introduced into the kidney initiate renal injury. Mol. Med. 2:297-312.

22. Schwarting, A., et al. 1999. IL-12 drives IFN-gamma-dependent autoimmune kidney disease in MRL-Fas(lpr) mice. J. Immunol. 163:6884-6891.

23. Bohle, A., et al. 1990. The consequences of tubulo-interstitial changes for renal function in glomerulopathies. A morphometric and cytological analysis. Pathol. Res. Pract. 186:135-144.

24. Nath, K.A. 1992. Tubulointerstitial changes as a major determinant in the progression of renal damage. Am. J. Kidney Dis. 20:1-17.

25. Moore, K.J., Yeh, K., Naito, T., and Kelley, V.R. 1996. TNF-alpha enhances colony-stimulating factor-1-induced macrophage accumulation in autoimmune renal disease. J. Immunol. 157:427-432.

26. Rovin, B.H., and Phan, L.T. 1998. Chemotactic factors and renal inflammation. Am. J. Kidney Dis. 31:1065-1084

27. Daha, M.R., and van Kooten, C. 2000. Is the proximal tubular cell a proinflammatory cell? Nephrol. Dial. Transplant. 6(Suppl):41-43.

28. Kelley, V.R., Diaz-Gallo, C., Jevnikar, A.M., and Singer, G.G. 1993. Renal tubular epithelial and $\mathrm{T}$ cell interactions in autoimmune renal disease. Kidney Int. Suppl. 39:S108-S115.

29. van Kooten, C., and Daha, M.R. 2001. Cytokine cross-talk between tubular epithelial cells and interstitial immunocompetent cells. Curr. Opin. Nephrol. Hypertens. 10:55-59.

30. Jevnikar, A.M., et al. 1991. Stimulated kidney tubular epithelial cells express membrane associated and secreted TNF alpha. Kidney Int. 40:203-211.

31. Wada, T., Naito, T., Griffiths, R.C., Coffman, T.M., and Kelley, V.R. 1997. Systemic autoimmune nephritogenic components induce CSF-1 and TNF-alpha in MRL kidneys. Kidney Int. 52:934-941.

32. Schwarting, A., et al. 1998. IFN-gamma limits macrophage expansion in
MRL-Fas(lpr) autoimmune interstitial nephritis: a negative regulatory pathway. J. Immunol. 160:4074-4081.

33. Shihab, F.S., Andoh, T.F., Tanner, A.M., Yi, H., and Bennett, W.M. 1999. Expression of apoptosis regulatory genes in chronic cyclosporine nephrotoxicity favors apoptosis. Kidney Int. 56:2147-2159.

34. Dooms, H., et al. 1998. Quiescence-inducing and antiapoptotic activities of IL-15 enhance secondary CD4+ T cell responsiveness to antigen. J. Immunol. 161:2141-2150.

35. Tagaya, Y., Burton, J.D., Miyamoto, Y., and Waldmann, T.A. 1996. Identification of a novel receptor/signal transduction pathway for IL-15/T in mast cells. EMBO J. 15:4928-4939.

36. Girard, D., Paquet, M.E., Paquin, R., and Beaulieu, A.D. 1996. Differential effects of interleukin-15 (IL-15) and IL-2 on human neutrophils: modulation of phagocytosis, cytoskeleton rearrangement, gene expression, and apoptosis by IL-15. Blood. 88:3176-3184.

37. Bulfone, P.S., et al. 1999. Death deflected: IL-15 inhibits TNF-alphamediated apoptosis in fibroblasts by TRAF2 recruitment to the IL-15Ralpha chain. FASEB J. 13:1575-1585.

38. Ruckert, R., et al. 2000. Inhibition of keratinocyte apoptosis by IL-15: a new parameter in the pathogenesis of psoriasis? J. Immunol. 165:2240-2250.

39. Bulfone, P.S., et al. 1997. Interleukin-15 protects from lethal apoptosis in vivo. Nat. Med. 3:1124-1128.

40. Ortiz, A., et al. 2000. Expression of apoptosis regulatory proteins in tubular epithelium stressed in culture or following acute renal failure. Kidney Int. 57:969-981.

41. Masuda, A., Matsuguchi, T., Yamaki, K., Hayakawa, T., and Yoshikai, Y 2001. Interleukin-15 prevents mouse mast cell apoptosis through STAT6-mediated Bcl-xL expression. J. Biol. Chem. 276:26107-26113.

42. Ophascharoensuk, V., et al. 1999. Obstructive uropathy in the mouse: role of osteopontin in interstitial fibrosis and apoptosis. Kidney Int. 56:571-580.

43. Bruzzi, I., Benigni, A., and Remuzzi, G. 1997. Role of increased glomerular protein traffic in the progression of renal failure. Kidney Int. Suppl. 62:S29-S31.

44. Matsuo, S., Morita, Y., Mizuno, M., Nishikawa, K., and Yuzawa, Y. 1998. Proteinuria and damage to tubular cells-is complement a culprit? Nephrol. Dial. Transplant. 13:2723-2726.

45. Oldfield, M.D., et al. 2001. Advanced glycation end products cause epithelial-myofibroblast transdifferentiation via the receptor for advanced glycation end products (RAGE). J. Clin. Invest. 108:1853-1863. DOI:10.1172/JCI200111951.

46. Hebert, M.J., et al. 1998. Acute nephrotoxic serum nephritis in complement knockout mice: relative roles of the classical and alternate pathways in neutrophil recruitment and proteinuria. Nephrol. Dial. Transplant. 13:2799-2803.

47. Quigg, R.J., et al. 1998. Blockade of antibody-induced glomerulonephritis with Crry-Ig, a soluble murine complement inhibitor. J. Immunol. 160:4553-4560.

48. Park, S.Y., et al. 1998. Resistance of Fc receptor-deficient mice to fatal glomerulonephritis. J. Clin. Invest. 102:1229-1238.

49. Mayadas, T.N., et al. 1996. Acute passive anti-glomerular basement membrane nephritis in P-selectin-deficient mice. Kidney Int. 49:1342-1349.

50. Rosenkranz, A.R., Mendrick, D.L., Cotran, R.S., and Mayadas, T.N. 1999 P-selectin deficiency exacerbates experimental glomerulonephritis: a protective role for endothelial P-selectin in inflammation. J. Clin. Invest. 103:649-659

51. Tipping, P.G., Huang, X.R., Berndt, M.C., and Holdsworth, S.R. 1994. A role for $\mathrm{P}$ selectin in complement-independent neutrophil-mediated glomerular injury. Kidney Int. 46:79-88

52. Fehniger, T.A., and Caligiuri, M.A. 2001. Interleukin 15: biology and relevance to human disease. Blood. 97:14-32.

53. Lloyd, C.M., et al. 1997. RANTES and monocyte chemoattractant protein-1 (MCP-1) play an important role in the inflammatory phase of crescentic nephritis, but only MCP-1 is involved in crescent formation and interstitial fibrosis. J. Exp. Med. 185:1371-1380.

54. Lugering, N., Kucharzik, T., Maaser, C., Kraft, M., and Domschke, W. 1999. Interleukin-15 strongly inhibits interleukin-8 and monocyte chemoattractant protein-1 production in human colonic epithelial cells. Immunology. 98:504-509. 